\title{
Building a Community of Connected ELT Professionals on Twitter
}

\author{
Bonnie Nicholas, Augusta Avram, Jennifer Chow, E Svetlana Lupasco
}

Although English language teaching professionals are committed to ongoing continuous professional development, economic and workload factors may impede their ability to attend a traditional 2-day annual conference. Teachers have turned to social media as an alternative approach to self-directed professional development. In particular, Twitter has become the choice of many educators with its potential for networking and collaboration. There are scheduled Twitter chats held regularly on a variety of topics of interest to language teaching professionals, including \#CdnELTchat. In addition, connected educators have built a community of practice on the Twitter platform and provide inspiration and support to their colleagues online. In this article, four connected educators who have found their community on Twitter share their stories of how they got started on Twitter, how they connected with each other, and what they value about the open Twitter platform.

Bien que les professionnels de l'enseignement de l'anglais s'engagent à poursuivre un perfectionnement professionnel continu, des facteurs économiques ou des charges de travail peuvent les empêcher d'assister à une conférence annuelle traditionnelle de 2 jours. Les enseignantes et enseignants trouvent dans les réseaux sociaux une solution de rechange qui leur permet de veiller à leur propre perfectionnement professionnel. Twitter, notamment, est le nouveau choix de nombreux éducateurs et éducatrices en raison des possibilités de réseautage et de collaboration qu'il présente. Des sessions de clavardage ont régulièrement lieu sur une variété de sujets présentant un intérêt pour les professionnels de l'enseignement des langues, et ce, notamment sur \#CdnELTchat. Qui plus est, les éducatrices et éducateurs connectés ont construit une communauté de praticiens sur la plateforme Twitter et fournissent une inspiration et un soutien à leurs collègues en ligne. Dans cet article, quatre éducatrices connectées qui ont découvert leur communauté sur Twitter décrivent comment elles ont commencé à se servir de Twitter, comment elles se sont connectées les unes aux autres, et ce qu'elles apprécient le plus sur la plateforme ouverte de Twitter.

KEYWORDS: Twitter, Personal Learning Network (PLN), community, connected, professional development

English language teaching (ELT) professionals have a long history of being committed to continuing professional development (CPD). Newly published 
research, program changes, and innovations in educational technology all contribute to the need for CPD. For some teachers, CPD is mandatory to maintain accreditation, as, for example, in Ontario. For everyone in ELT, CPD is essential if teachers are to continue to learn their craft and improve their classroom practice, yet keeping up with rapid developments in the field of second language acquisition (SLA) can be a daunting prospect and can become just one more thing to check off. With increased demand for language training and expanding professional and administrative responsibilities, teachers working in ELT can find themselves feeling stretched. Balancing work and personal life with expected professional development (PD) is increasingly a challenge for many practitioners. Conferences, long considered the gold standard for CPD, offer an opportunity to hear directly from experts about the latest research in the field as well as offering a place to connect with colleagues working in other geographical areas, other contexts, and other teaching specialties, and to network and share ideas and good practices. A once-a-year conference can be stimulating but can leave teachers feeling disconnected the other 51 weeks of the year.

Visser, Evering, and Barrett (2014) have identified other drawbacks to the traditional conference, including the top-down approach, the lack of followup, and a general neglect of classroom practice. As well, the financial cost and time commitment to attend conferences can place them out of reach of many teachers (Hyndman, 2018). Even then, it is likely that family and personal responsibilities mean that not all teachers will be able to avail themselves of the opportunity to attend an out-of-town conference, even for just a couple of days a year. The result is that ELT professionals, already stretched and stressed, can also feel isolated not only from their colleagues working in other contexts, but also disconnected from new trends in the field.

Concurrent with this decrease in traditional face-to-face learning opportunities has been an explosion of new technology and tools that have the potential to enhance language teaching and learning. Many of these edtech tools could ease teachers' workload, if they could only learn about them. Teachers are creating resources and are willing to share, but an annual conference affords limited opportunity for collaboration. The imperative for CPD coupled with the growing inaccessibility of conferences has left instructors to seek out alternative forms of learning, PD that is "praxis oriented, . . . dynamic and flexible" (Ross, Maninger, LaPrairie, \& Sullivan, 2015, p. 57). Books, journals, workshops, reading groups, and meetings can also be rich sources of ongoing PD, though these may also have limitations including cost, access, and time commitment. As well, some of these may have a topdown direction and lack learner agency. 


\section{Social Media for Professional Development}

New approaches to learning and social media have opened new windows of opportunity for continuous learning, and these are beginning to permeate the workplace (Manca \& Ranieri, 2017). No longer do ELT professionals have to wait until conference season to learn something new or miss out on the learning because they lack the resources to participate in conferences. In recent years, LinkedIn, Twitter, Facebook groups, webinars, Massive Open Online Courses (MOOCs), edcamps, online courses, and certificates, and even complete online conferences have all proven themselves to be viable alternatives to the traditional face-to-face conference. Of these, Twitter, now in its second decade, has long been a favourite platform for celebrity gossip and links to ubiquitous cat videos. More recently, Twitter has gained notoriety as a political platform. Despite this reputation, Twitter has become the online platform of choice for many educators, and ELT professionals are no exception. While there is a robust community of educators actively pursuing CPD on Twitter, there are many more who are still waiting to be convinced of the benefits of developing a Personal Learning Network (PLN) through this particular social media tool. That educators pursue this form of networked PD even without a credentialing option is a testament to their commitment to lifelong learning (Lupasco, 2017).

The authors of this article are four such educators. Augusta, Jennifer, Svetlana, and Bonnie met online through a bi-monthly, pan-Canadian Twitter chat, \#LINCchat (now rebranded \#CdnELTchat, for Canadian ELT chat). Svetlana Lupasco and Nathan Hall were the original co-moderators of \#LINCchat (Language Instruction for Newcomers to Canada), first under the auspices of LISTN (Language Instruction Support and Training Network) and then BC TEAL (British Columbia Teachers of English as an Additional Language). Augusta, Jennifer, and Bonnie were enthusiastic participants who joined the team some time after the chats were well-established. Jennifer and Augusta both work in the lower mainland of British Columbia, so they knew each other professionally. Svetlana is in Ontario and Bonnie, in Alberta.

These four instructors created a supportive professional relationship online. They knew each other for some time only online, until they all met for the first time at a BC TEAL conference in Vancouver where they were presenting together about how they had connected and built a community of practice on Twitter, having planned and prepared the presentation using online tools. Each of these ELT practitioners has now been active on Twitter for a few years, forging collaborative professional relationships and creating a PLN that has become an essential part of their CPD. PLNs are characteristically "individualized and user-centered" (Davis, 2015, p. 1553). Svetlana discusses how she came to discover this user-centred efficacy of Twitter for PD: 
My encounter with Twitter started when I was taking a year off teaching and needed to stay connected professionally. I did not know anything about Twitter or how to use it for professional development, but I wanted to learn what other teachers were sharing on it. I chose Twitter mainly because it was very easy to connect with others by just following their profiles; I did not know anyone in the field at that time and would not dare to reach out to anyone in person. I set up an account and started following a few educators, mainly those whose work I knew from reading their blogs. By scanning through their tweets, I spotted hashtags, researched them, and a whole new world opened to me. I could not get enough of it; I loved the brevity of tweets and that teachers were so generous by sharing their ideas and classroom experiences.

\section{Personalized Professional Development}

Educators who use Twitter recognize its value as a useful tool for self-directed PD, networking, and collaboration (Davis, 2015). Twitter is not a replacement for face-to-face interactions but, instead, is a useful tool to supplement already established face-to-face practices (Megele, 2014; Carpenter \& Krutka, 2014). Most conferences now have an official hashtag, allowing attendees to tweet out upcoming sessions, insights from presenters, and links to references and resources (Ross et al., 2015, p. 69). Augusta describes how tweets at conferences have helped her to participate and learn, even when she is not physically present at a conference.

Twitter as a conference backchannel helps me stay focused, extract main ideas, and take note of new ideas and resources. The backchannel basically helps me remember things to be used or explored later; it also helps me grow my PLN. Following tweets from conferences that I can't attend means that I always have a chance to learn something new.

While there can be a great deal of background noise on a Twitter timeline, judicious choices and careful curation make it possible to filter out unwanted content and create a focused information stream. Augusta goes on to explain how she sees this flow of information as an engaging tool for PD:

Twitter offers an abundance of ideas, perspectives, and resources, with daily doses of self-directed development and professional news. Twitter is completely integrated in my daily life; there's no need to schedule/reserve time for PD. Twitter provides PD opportunities anytime anywhere, which is very convenient in the context of our busy lives; I also enjoy getting notifications on my Apple watch. 
To me, this doesn't feel like an imposition, on the contrary, it helps me stay in touch.

For Augusta, learning has become "a lifelong system of networked activities" (Cain \& Chretien, 2013, p. 4). Other researchers have found that using Twitter "saves time in sharing information" (Ross et al., 2015, p. 64).

The search feature of Twitter allows the site to be used as a vehicle for content curation. Searching for a hashtag such as \#CdnELTchat, \#ELL, \#ELT, \#EAL, \#ESL, \#ELLchat, \#TESOL, \#edtech, \#tleap, or \#TESLCanada will bring up all tweets that have used that particular hashtag. Entering keywords (with or without the ubiquitous hashtag symbol) allows for narrow search parameters. Jennifer describes how she uses Twitter to find solutions to teaching challenges:

When I encounter a problem in my teaching, I look to Twitter for timely PD. I search my PLN for blog posts, podcasts, discussions and suggestions, which could change my practice. For example, when I felt uncomfortable with the way I was teaching listening, I went on a mission to search \#ELT \#listening hashtags on Twitter to transform my practice. On Twitter, I collated a wealth of information on a more balanced approach and informed myself with how to incorporate bottom-up listening skills with every task.

\section{Connecting with ELT Professionals}

Twitter affords a unique opportunity to connect with other professionals. Educators comprise a significant and growing group of Twitter users, some with thousands of followers. Through Twitter, these four ELT practitioners have grown personally and professionally, forming relationships that transcend the online environment. While Twitter meet-ups at conferences have provided opportunities to connect in-person with one's online PLN, the majority of the interaction takes place online. Here is Jennifer's explanation of what Twitter has meant to her professionally:

Interacting with other educators on Twitter saved me from being on the verge of burnout and isolation. As an introvert, I often felt exhausted at the end of the day because teaching is such a social act. It was also difficult for me to initiate conversations with colleagues because of a lack of confidence in my abilities and knowledge as a teacher. I subscribed to ELT Journals and went to various conferences, but rarely did I feel confident enough to interact much with other attendees. At one point, I felt like changing careers, but discovering Twitter enabled me to fight feelings of isolation and find connections to other educators. Instead of feeling vulnerable and isolated when I am faced with teaching challenges, I feel that my 
PLN on Twitter can provide a supportive and nurturing environment. Engaging on Twitter for PD shaped my teacher identity and gave me a sense of belonging. This renewed sense of belonging empowered me to find a voice with my colleagues as well. Now when I go to conferences, I feel comfortable reaching out to other attendees and feel a strong sense of community.

Actively participating in a community of practice through a PLN "allows educators to transform the paradigm of the isolated teacher into that of a lifelong, connected learner" (Ross et al., 2015, p. 58). Carpenter and Krutka (2015) found that educators viewed Twitter interactions as a way to combat professional isolation and connect them with valued colleagues and leaders in the field. Like Jennifer, Bonnie sees herself as an introvert who has found that Twitter can be a source of focused, self-directed PD, which she finds particularly valuable:

For me, Twitter has been a place where I can connect with my colleagues across the country on my own time and in my own way. I love teaching and learning, but I find teaching, meetings, workshops, and conferences - anything with that face-to-face component-to be really exhausting, so for me Twitter fills a need for professional development that I can do on my own time and in my own space. I value the asynchronous, conversational nature of Twitter-and if that seems like an oxymoron, well, that's the nature of Twitter.

Augusta had a similar experience on Twitter, finding that the online relationship can lead to a more connected professional relationship with other ELT practitioners:

Connecting with like-minded professionals breaks the isolation, creates opportunities for ongoing dialogue, and makes me feel supported. A retweet or a like equals a nod or a smile; it's never impersonal, there is always someone behind it. Some of my best professional relationships and collaborations started on Twitter. Later, when we met face to face, it felt like we had already known each other quite well. Our \#CdnELTchat group [the four of us] is the best example.

As a relatively recent phenomenon, Twitter is underresearched in academia but the richness of the Twitter community of practice has been noted by bloggers and others writing in the field (see, for example, Ferlazzo, 2018, and Gonzalez, 2018). Weston has described that initial discovery of an online, connected community: "For a previously disconnected teacher, a Velcro moment is exhilarating. ... Connecting with people, who validate and inspire the teacher to grow and think anew spurs her to seek more Velcro moments" $(2015$, n.p.). This idea of forming connections resonated with Svetlana, who 
discovered for herself the potential of connecting with other ELT professionals via Twitter:

I realized how powerful Twitter was as it gave me access to other teachers' practice, classrooms, reflections, successes and failures, resources, and classroom activities. I felt many things: inspired to challenge myself; relieved to see that all teachers had their own challenges; enthusiastic to anything recommended by teachers. I found my voice and motivation to try new things in my classes and report back to my community on Twitter. As a result, I started tweeting more about my teaching and connecting with other \#CdnELT teachers.

Visser et al. argue that the always-accessible, informal PD available on Twitter can "become embedded in the teacher's daily routine, which can lead to transformation of practice" (2014, p. 397). This transformation has been a common experience for these four educators; they have all brought what they learned on Twitter into their teaching practice.

\section{Learning through Twitter Chats}

Twitter chats are one way that teaching professionals engage in online PD with their peers. Most chats take place in the evening (depending on the time zone) so ELT professionals make a choice to take part after their regular working hours. These chats are characterized by a connectivist approach to learning, as participants share ideas and actively participate in the discussion. The diversity of opinion, the necessity of nurturing connections, and the stream of new information are all features of connectivism (Siemens, 2005). As an early participant in Twitter chats, Svetlana found what has been described as an "amplification of learning, knowledge and understanding through the extension of a personal network" (Siemens, 2005, p. 5). Svetlana tells how she got started in her leadership role:

I was invited by Nathan Hall to co-moderate a Twitter chat, with the idea to create a space for the LINC community to connect and support each other. Being a \#LINCchat moderator meant to assume a leadership role that came with a greater sense of responsibility, but also a greater sense of belonging to a professional community. Every single chat was fast, exhilarating and informative.

Although the chats themselves are brief (no more than an hour) and fastpaced, the ideas generated can lead not just to change in practice but to professional introspection and reflection. Jennifer talks about the reflective practice that Twitter chats have fostered in her teaching:

The informal but purposeful discussions and interactions that take place on Twitter have the power to stimulate change and reinforce 
what I am doing in the classroom. Educators from across Canada and other countries discuss their ideas, share their current successes and challenges on an announced topic, allowing for a collective reflection. Participants on \#CdnELTchat then can access this collective reflection and create a new understanding and knowledge which informs their teaching practice.

Twitter chats such as those described by Jennifer offer a rich learning environment in which self-directed learners similar to apprentices can access and learn from many more knowledgeable others who can give support in developing knowledge, skills, and capabilities (Megele, 2014). Those who are new to Twitter and Twitter chats can choose to lurk-observe from the sidelines - until they feel comfortable participating. Following chat participants is one way to make connections and get to know who in the Canadian and worldwide ELT community is active on Twitter. Like Jennifer, Bonnie has found Twitter chats to be part of a vibrant online community of practice:

Twitter is a place to connect, to build relationships, and to learn and grow as a teacher. And because I can do this on the bus with my phone or in the evenings with my cup of tea before I go to bed, Twitter has freed me from the constraints of formal learning. In particular, I have learned so much from our \#CdnELTchat discussions. These chats are like several conversations going on at once, with practitioners from across the country and around the world. Chats are a great way to be introduced to the value of Twitter. By following the chat hashtag, you can lurk on the chat until you're comfortable participating, and then you can follow those people who participated in the chat and see what other things they're posting and who they're following. So you can grow your PLN organically just from that initial tentative foray into chat.

The lurking that is possible on Twitter is a form of passive participation in a community of practice. This peripheral or marginal "non-participation" may evolve into active participation, as individuals see the value of fuller participation (Wenger, 1998, p. 164). Actively participating in chats brings new insights and differing perspectives, as Svetlana found:

What I like the most about participating in a Twitter chat like \#CdnELTchat is the different perspectives about the same topic: participants are often from different streams of ELT [e.g., LINC, EAP (English for Academic Purposes), credit/non-credit, adults/young learners] and can be located anywhere in the world. Being able to get different perspectives has broadened my own understanding of our field; it also made me more open to sharing my views and knowledge. I've had multiple opportunities to do both share my 
professional expertise and learn from experts [learn fast, free of charge, from experts all over the world].

\section{Twitter and Professional Growth}

There is always a risk of isolation when practitioners are divided by great distances although they may be working in similar contexts. Social media has created opportunities to change this; George Couros (2015) has written that "isolation is now a choice educators make." Jennifer made the choice to connect, and found that the resilience she developed through her Twitter PLN helped counter isolation:

I also get exposure to other educators who work in different environments and have different limitations. They can give me fresh insights into classroom problems, which in turn mitigate isolation and builds my resilience. My resilience grew because of a sense of belonging I felt on Twitter. Seeing what other committed and passionate educators were doing motivated me to set targets for myself to reach. This renewed sense of resilience was mediated by the positive interactions I had access to on Twitter. Having access to my PLN on Twitter means being able to interact with professionals who continuously look for and share learning opportunities, act on these opportunities and then reflect on the change.

Open platforms such as Twitter have been linked to the rise in Open Educational Resources (OERs), leading some to describe this kind of self-directed PD as Open Educational Practice or OEP, "where professionals develop new practices around the use of social media and social networking resources" (Kaatrakoski, Littlejohn, \& Hood, 2017, p. 47). Bonnie reflected about the benefits she has received from being an active participant in her PLN on Twitter:

The openness that Twitter demands has been a significant factor in building my confidence. Although I have a Master's degree in TESL and have been teaching for 10 years, sometimes I think what I know and do is not worth sharing. Twitter has taught me that there is much value in sharing ideas, in being open about what we are doing, and in learning from each other.

Bozarth (2014) describes this openness as "working out loud." She suggests that "time spent on public conversations on Twitter . . can tell a lot about people's willingness to share with little expectation of any return" (p. 53). The return comes from the engagement with the community of practice. Building a PLN through Twitter takes time but the commitment can be as little or as much as one chooses. Augusta shares how her professional learning changed after she began using Twitter: 
Before Twitter, my learning was fragmented and happening in isolation, and it came mainly from attending an annual conference or purchasing books or research articles [limited funds never allowed for much though]; now, I feel immersed in a flow of information that I can use at my convenience, with the occasional bingeing.

The information flow has been described as "new mobilities," where learning is portable, networked, and has become "part of broader changes in people's lives and ways of learning" (Erstad, 2016, p. 95).

\section{Social Media and Learner Agency}

Twitter provides a degree of autonomy not afforded by more traditional sources of CPD. In traditional PD, the subject matter content may be determined by the mandate of the organizing body, the overarching theme of the conference, and the sessions chosen by the proposal reviewers. Viewed through an instructional design lens, conferences can be seen as an example of push learning, where professionals and delegates are pushed to different types of learning. This kind of learning is typically top-down, directed by institutions or mandated by funders. In contrast, Twitter can be viewed as pull learning, where individuals through their own agency are pulled toward the kind of learning they have determined they need to fill gaps in their own knowledge, based on their own experience. Augusta articulates how this agency has impacted her growth as an ELT practitioner:

Twitter helps me understand and shape my professional identity, with every like, retweet, tweet and reply. It constantly makes me revisit the ideas that are the foundation of my philosophy of teaching; sometimes they are reinforced and other times they are challenged. I enjoy being exposed to (and even bombarded with) ideas and information. Some of these ideas stay with me and most probably guide some of my choices in terms of tweets to read and explore further. For example, the ones that are relevant to my teaching context and interests usually evolve into practical applications for my classes and students.

For Bonnie, as well, this agency has been an important part of her development as a teacher, pushing the boundaries of traditional PD:

Twitter has helped me develop my growth mind-set as a teacher. I've become more innovative as I learn about new tools, new research, and new approaches on Twitter, because a lot of early adopters are on Twitter and they're sharing what they know. I find Twitter to be an open, supportive, collaborative place to connect with other teachers. My PLN supports me by sometimes agreeing with my posts and sometimes challenging my tweets. So my PLN always forces 
me to think and to be thoughtful about my contributions to the conversation.

Svetlana, too, has found that Twitter has refined her professional identity:

Looking back, I think that being actively engaged on Twitter and connecting with practitioners in my field has changed my professional reality as well as my professional aspirations. My involvement in \#CdnELTchat marked a new phase of my engagement on Twitter.

Although there is a risk of confirmation bias on any social media platform, educators are cognizant of their public profile as well as their association with a particular program or institution and represent themselves accordingly. Many educators use Twitter only for CPD, forbearing comment on entertainment news or political issues. This makes it possible to tailor a Twitter feed to see only relevant issues.

\section{Conclusion}

ELT professionals may be reluctant to join Twitter, perhaps due to time constraints, perhaps because of the perceived frivolous nature of the platform, and perhaps in part from the fear that the character limit imposes undue constraints on conversations. But Augusta, Jennifer, Svetlana, and Bonnie value the self-directed CPD and openness that they have found through Twitter, despite the limitations of the platform. Social media affords a unique opportunity to create a PLN by facilitating connections with other language teachers, not just in Canada but from around the globe. These four teachers are active members of the robust community of educators who connect online 280 characters at a time every day on Twitter. Twitter allows each of these four ELT professionals "to transform the paradigm of the isolated teacher into that of a lifelong, connected learner" (Ross et al., 2015, p. 58). They hope that the evolving open educational practice that they embrace on Twitter will one day be widely recognized not just as a useful form of CPD but also as a legitimate method of teacher development.

\section{Acknowledgements}

We are grateful to Nathan Hall (@nathanghall) and BC TEAL for their vision in launching and supporting \#CdnELTchat. We would also like to thank the dedicated ELT professionals across Canada and around the world who have made our own professional development on Twitter such a rich and rewarding experience.

\section{The Authors}

Augusta Avram (@LINCInstructor) is an educator interested in the impact technology has on the way we learn, connect, and share our voices. In her spare time, she enjoys the outdoors. 
Jennifer Chow (@jennifermchow) is passionate about learning how technology can empower her students. Twitter has enabled her to be connected as an educator, a mother, and an active citizen, so she is motivated to find similar opportunities for her students.

Svetlana Lupasco (@StanzaSL) is an Adult ESL professional with a special interest in adult ESL literacy, e-learning, and collaborative PD. She teaches at the Woodsworth College TESOL Certificate program, University of Toronto. She has co-moderated \#CdnELTchat since 2015.

Bonnie Nicholas (@EALstories) teaches LINC classes at NorQuest College in Edmonton, where she has taught both blended and fully online classes. She values Twitter for the excellent connected professional development that it offers.

\section{References}

Bozarth, J. (2014). Show your work: The payoffs and how-to's of working out loud. San Francisco: Wiley.

Cain, J., and Chretien, K. (2013). Exploring social media's potential in interprofessional education. Journal of Research in Interprofessional Practice and Education, 3(2), 1-7.

Carpenter, J. P., \& Krutka, D. G. (2015). Engagement through microblogging: Educator professional development via Twitter. Professional Development in Education, 41(4), 707-728.

Couros, G. (2015). The innovator's mindset: Empower learning, unleash talent, and lead a culture of creativity. San Diego, CA: Dave Burgess Consulting, Inc.

Davis, K. (2015). Teachers' perceptions of Twitter for professional development. Disability and Rehabilitation, 37:17, 1551-1558. doi:10.3109/09638288.2015.1052576

Erstad, O. (2016). Literacy spaces, digital pathways, and connected learning: Teachers' professional development in times of new mobilities. In M. Knobel \& J. Kalman (Eds.), New Literacies and Teacher Learning (89-109). New York: Peter Lang.

Ferlazzo, L. (2018). Classroom Q \& A. [Blog post]. http://blogs.edweek.org/teachers/classroom_ qa_with_larry_ferlazzo/

Gonzalez, J. (2018). So you have a Twitter account. Now what? [Blog post]. The Cult of Pedagogy. https://www.cultofpedagogy.com/

Hyndman, B. (2018). Why teachers are turning to Twitter. The Conversation. Retrieved from http:// theconversation.com/why-teachers-are-turning-to-twitter-94582

Kaatrakoski, H., Littlejohn, A., \& Hood, N. (2017). Rethinking professional learning in higher education: A study on how the use of Open Educational Resources triggers the adoption of Open Educational Practice. Qwerty-Open and Interdisciplinary Journal of Technology, Culture, and Education, 12(2), 46-63.

Lupasco, S. (2017). Professional learning and networking stories of Canadian TESL practitioners engaged in \#LINCchat. Manchester, UK: The University of Manchester/British Council.

Manca, S., \& Ranieri, M. (2017). Reshaping professional learning in the social media landscape: Theories, practices and challenges. Qwerty-Open and Interdisciplinary Journal of Technology, Culture, and Education, 12(2), 5-11.

Megele, C. (2014). Theorising Twitter Chat. Journal of Perspectives in Applied Academic Practice, 2(2).

Ross, C. R., Maninger, R. M., LaPrairie, K. N., \& Sullivan, S. (2015). The use of Twitter in the creation of educational professional learning opportunities. Administrative Issues Journal: Connecting Education, Practice, and Research, 5(1), 55-76. doi:10.5929/2015.5.1.7

Siemens, G. (2005). Connectivism: A learning theory for the digital age. International Journal of Instructional Technology and Distance Learning, 2(1), 3-10.

Visser, R. D., Evering, L. C., and Barrett, D. E. (2014). \#TwitterforTeachers: The implications of Twitter as a self-directed professional development tool for K-12 teachers. Journal of Research on Technology in Education, 46(4), 396-413.

Wenger, E. (1998). Communities of practice: Learning, meaning and identity. Cambridge: Cambridge University Press. 
Weston, M. E. (2015). Velcro moments: When teachers connect. [Blog post]. Retrieved from https://shiftparadigm2011.wordpress.com/2015/12/13/velcro-moments-when-teachers-connecting-with-teachers/ 